AperTO - Archivio Istituzionale Open Access dell'Università di Torino

Neutrophil recruitment in the reperfused-injured rat liver was effectively attenuated by repertaxin, a novel allosteric noncompetitive inhibitor of CXCL8 receptors: a therapeutic approach for the treatment of post-ischemic hepatic syndromes

This is the author's manuscript

Original Citation:

Availability:

This version is available http://hdl.handle.net/2318/38995

since

Terms of use:

Open Access

Anyone can freely access the full text of works made available as "Open Access". Works made available under a Creative Commons license can be used according to the terms and conditions of said license. Use of all other works requires consent of the right holder (author or publisher) if not exempted from copyright protection by the applicable law. 


\title{
NEUTROPHIL RECRUITMENT IN THE REPERFUSED-INJURED RAT LIVER WAS EFFECTIVELY ATTENUATED BY REPERTAXIN, A NOVEL ALLOSTERIC NON- COMPETITIVE INHIBITOR OF CXCL8 RECEPTORS: A THERAPEUTIC APPROACH FOR THE TREATMENT OF POST-ISCHEMIC HEPATIC SYNDROMES
}

\author{
B. CAVALIERI*, M. MOSCA'*, P. RAMADORI, M.-G. PERRELLI, L. DE SIMONE, F. \\ COLOTTA $^{\prime}$, R. BERTINI', G. POLI and J. C. CUTRİN \\ Laboratory of Experimental Liver Pathology, Department of Clinical and Biological Sciences, \\ University of Turin; 1 Dompè S.p.A., L'Aquila, Italy
}

Received September 16, 2004 -Accepted October 1, 2004

\section{- $B C$ and MM contributed equally to this work.}

Hepatic reperfusion injury represents a crucial problem in several clinical situations including liver transplantation, extensive hepatectomy and hypovolemic shock with resuscitation. Repertaxin is a new noncompetive allosteric blocker of interleukin-8 (CXCL8) receptors, which by locking CXCR1/R2 in an inactive conformation, prevents receptor signaling and polymorphonuclear leukocyte (PMN) chemotaxis. The present study shows that repertaxin dramatically prevents rat post-ischemic hepatocellular necrosis $(\mathbf{8 0} \%$ of inhibition) and PMN infiltration (96\% of inhibition) at a clinically-relevant time (24 h) of reperfusion. Treatment with repertaxin by continuous infusion is demonstrated to be the optimal route of administration of the compound especially in view of its clinical threrapeutic use. Because repertaxin has proven to be safe and well tolerated in different animal studies and in phase I studies in human volunteers, it is in fact a candidate novel therapeutic agent for the prevention and treatment of hepatic post-ischemic injury.

Hepatic ischemia-reperfusion injury remains an unavoidable problem in liver transplantation surgery, extensive hepatectomy, and hypovolemic shock with resuscitation (1-2). In transplantation, ischemiareperfusion injury is clearly a major determinant of early graft function. Initial poor function is seen approximately in $10-20 \%$ of transplanted livers, and is associated with higher graft failure, re-transplantation, and mortality within the first three months (3-6). Other possible important consequences due to ischemia/reperfusion injury include clinical entities with high incidence of morbidity and mortality such as liver failure, multiorgan dysfunction syndrome and/or adult respiratory distress syndrome, with an elevated rate of mortality $(5,7-8)$.
Recent studies performed in appropriate experimental models have focused the attention on the involvement of $\mathrm{CXC}$-chemokines and polymorphonuclear neutrophils (PMN) as the major cause of post-ischemic hepatic injury (9-14). Accumulation of activated PMN in the hepatic sinusoids adhere to endothelial cells and hepatocytes causing directly microvascular dysfunction and hepatocyte damage by the generation of reactive oxygen species and myeloperoxidase (MPO)-derived oxidant. Moreover, oxidative stress may also deactivate endogenous anti-proteases facilitating the hepatocellular damage associated with PMN release of proteolytic enzymes (15-19). In addition, infiltrated PMN in hepatic sinusoids can obstruct blood flow and contribute to

Key words: hepatic post-ischemic injury, CXC-chemokines, inflammation, repertaxin

Mailing addiess: Dr. Juan C. Cutrin

Laboratorio di Patologia Epatica Sperimentale,

Dipartimento di Scienze Cliniche e Biologiche,

Università Degli Studi di Torino, Regione Gonzole 10,

10043 Orbassano, Torimo, Italy

Phone: 0039011 670-5422; FAX: $0039011670-5424$

e-mail: jc.cutrin@unito.it

0394-6320(2005)

Copyright 0 by BPOLFe $5=5$

This publication and/or articice is for individual use only and may not be further reproduced without writien pernission from the copyright holder. Unauthorized reproduction may tesults in financial and other penalties 
create nutritional perfusion alterations (20).

It is becoming generally well accepted that leukocyte trafficking into the ischemic injured liver is a process likely dependent of local gradients of chemotactic factors, e.g. PMN-CXC chemokines like CINC-1/CXCL1 and MIP-2/CXCL2, the rat equivalents of human interleukin-8 (CXCL8; 10-13). The importance played by the CXC chemokines in the pathogenesis of ischemic/reperfusion damage raises the possibility that PMN recruitment may be attenuated through inhibition of CXCL1 and CXCL2. Consistently, anti-chemokine strategies, including neutralizing antibodies, N-terminal modified chemokines and G-protein coupled receptor (GPCR) molecule antagonists have been used to prevent experimental reperfusion injury (21-22).

We have very recently described repertaxin, a noncompetitive allosteric blocker of the CXCL8 receptors CXCR1 and CXCR2. Repertaxin is a new receptor inhibitor with a unique mechanism of action: it binds CXCL8 receptors and disrupts receptor signaling downstream events without affecting CXCL8 binding to its receptors (23): Repertaxin was also proven to be efficacious in preventing PMN recruitment and hepatocellular necrosis in the rat liver exposed to ischemia-reperfusion injury (23).

In order to determine the potential clinical application of repertaxin here we propose to further evaluate the efficacy of this compound in the prevention of post-ischemic damage of the liver. To this aim, the efficacy of repertaxin was evaluated 24 $h$ after liver reperfusion, a crucial reperfusion end point characterized by extensive hepatocellular necrosis and maximum PMN infiltration (24). Along the same line, this time of reperfusion seems to constitute a critical point in patient outcome after a clinical situation of post-ischemic liver injury. Next, the optimal schedule of treatment of repertaxin was determined in the same experimental model. The results reported hereafter show that repertaxin treatment dramatically reduced PMN infiltration and hepatocellular necrosis $24 \mathrm{~h}$ after reperfusion. Accordingly, the pharmacokinetic profile of repertaxin and its chemical-physical properties in animal treatment by continuous infusion was observed to be the optimal schedule of administration of the compound.

\section{MATERIALS AND METHODS}

\section{Reagents}

Repertaxin is $R(-)$-2-(4-isobutylphenyl) propionyl methansulfonamide L-lysine salt (Dompé S.p.A., L'Aquila, Italy).

\section{Animals}

All the procedures were performed in the animal facilities according to ethical guidelines for the conduction of animal research (Authorization from the Italian Ministry of Health N. 271/95-B D.Lvo 116/92; Gazzetta Ufficiale della Repubblica Italiana N. 40, February 18, 1992; EEC Council Directive 86/609 OJ L 358, 1 December 12, 1987 ; NIH Guide for the Care and Use of Laboratory Animals, NIH Publication N. 85-23, 1985). Male Sprague-Dawley rats (Harlan-Nossan, Correzzana, Udine, Italy) were used. They were kept in a temperature-controlled environment with a $12 \mathrm{~h}$ light-dark cycle and allowed tap water and standard rat chow pellets ad libitum.

\section{Sturgery for hepatic ischemia/reperfusion}

After anesthesia with a solution of tiletamina clorohydrate and zolazepam clorohydrate (1:1) in $0.9 \%$ sterile $\mathrm{NaCl}$ solution $(100 \mu \mathrm{l} / 100 \mathrm{~g}$ body weight, i.p.), rats were positioned in a heat pad to maintain their body temperature at $37.5 \pm 0.5^{\circ} \mathrm{C}$ and monitored with a rectal temperature probe. Laparotomy was carried out through a midline incision. The liver was gently exposed and subjected to selective inflow occlusion of the median and left lateral lobes by clamping the corresponding portal triad with a micro vascular clamp (25). At the end of 60 min ischemia, the ischemic lobes were allowed to reperfuse by removing the clamp. At the end of the reperfusion phase (12 and $24 \mathrm{~h}$ ), the rats were killed under anesthesia by exsanguination and specimens of blood and reperfused lobes were taken for morphological and biochemical determination.

\section{Surgery for blood collection}

The day before repertaxin administration, animals were weighed and anaesthetized with a solution of tiletamina clorohydrate and zolazepam clorohydrate $(1: 1)$ in $0.9 \%$ sterile $\mathrm{NaCl}$ solution ( $100 \mu \mathrm{l} / 100 \mathrm{~g}$ body weight, i.p.). Then, the left jugular vein was cannulated using a silicone medical grade catheter $(0.28$ inches ID, 0.47 inches OD, Silastic ${ }^{(\mathbb{B})}$, Dow Corning, U.S.A.) filled with heparin solution $(2.8 \mathrm{mg} / \mathrm{ml} ; 506 \mathrm{US}$ units $/ \mathrm{ml})$ and marked $2.5 \mathrm{~cm}$ from the tip. The catheter was inserted $2.5 \mathrm{~cm}$ along the vein. To verify the patency of the cannula, a small amount of blood was sucked into the catheters with a $1-\mathrm{ml}$ syringe. $100 \mu l$ of heparin solution were then injected into the cannulated vein. The day after the surgery, before 
administration of the test compound, $100 \mu l$ heparin solution was injected again into the cannulated vein.

\section{Preparation and implantation of the pumps}

The pumps (Alzet Osmotic Pump, Model 2ML1, Alza Corp., Palo Alto, CA) were filled with repertaxin or $0.9 \%$ sterile $\mathrm{NaCl}$ solutions according to the instructions of the supplier. Animals were weighed and anesthetized. Then, pumps were implanted subcutaneously. A small incision was made in the skin between the scapulae and, using a hemostat, a pocket was formed by spreading apart the subcutaneous connective tissues. The pump was inserted into the pocket with the flow moderator pointing away from the incision. The skin incision was closed with wound clips.

\section{Determination of repertaxin plasma levels}

Plasma was obtained from heparinised blood by centrifugation at $2000 \mathrm{x} \mathrm{g}$ for 10 minutes. The bioanalytical method based upon a high performance liquid chromatographic (HPLC) procedure involved the extraction of repertaxin and internal standard from aliquots of rat plasma $[200 \mu 1$ mixed with hydrochloric acid (50 $\mu \mathrm{I}, 5.8 \mathrm{M}$ ) into hexane/propan $2-\mathrm{ol}(3 \mathrm{mI} 9: 1, \mathrm{v} / \mathrm{v})$ or ethyl ether $(3 \mathrm{ml})]$. The extracts were evaporated to dryness under vacuum and the residues were reconstituted in acetonitrile/water $(200 \mu 1,8: 2, \mathrm{v} / \mathrm{v})$ or methanol/water $(200 \mu \mathrm{l}, 1: 1, \mathrm{v} / \mathrm{v})$. Aliquots were injected onto a Hypersil C18 BDS, $5 \mu \mathrm{m}$ or an X-Terra MS, $2.5 \mu \mathrm{m}$ analytical column and repertaxin and internal standard were chromatographed and detected by UV absorbance at 223 $n$ m or ESI-MS in positive ion mode, depending on the expected concentration of the analyte in the biological samples (being the HPLC-MS more sensitive than the HPLC-UV method).

\section{Experimental design: Protocol I}

First aim: to determine an appropriate schedule of treatment to evaluate the efficacy of repertaxin in preventing hepatic post-ischemic injury by repeated administration of the compound, the pharmacokinetic profile of repertaxin was evaluated in rats exposed to liver ischemia/reperfusion injury. Animals received two doses of repertaxin $(15 \mathrm{mg} / \mathrm{kg}$ ), i.v. (through the posterior cava vein) 15 min before reperfusion and s.c. $2 \mathrm{~h}$ after reperfusion. Blood samples (about $400 \mu 1$ ) were withdrawn from the cannulated jugular vein using a $1-\mathrm{ml}$ syringe. The blood samples were collected into Eppendorf tubes at the following times: $60,120,130,240,360 \mathrm{~min}$, $8 \mathrm{~h}$ and $12 \mathrm{~h}$ after i.v. injection. The withdrawn blood was replaced with $500 \mu \mathrm{l}$ of a heparin solution $(0.14 \mathrm{~g} / \mathrm{ml} ; 25.3$ US units/ml).

Second aim: to evaluate the efficacy of repeated administrations of repertaxin in preventing post-ischemic injury, the following experimental groups were studied.

Group 1: Sham: Animals were only subjected to laparotomy.

Group 2: Vehicle treated : Animals were submitted to 60 min of ischemia followed by $12 \mathrm{~h}$ or $24 \mathrm{~h}$ of reperfusion. Rats were treated with $0.9 \%$ sterile $\mathrm{NaCl}$ solution. The first treatment was given $15 \mathrm{~min}$ before the reperfusion phase (i.v), and then every two hours for three times after re-flow (s.c.)

Group 3: Repertaxin treated: Animals received two (12h reperfusion) or four doses (24h reperfusion) of repertaxin (15 mg/kg) dissolved in $0.9 \%$ sterile $\mathrm{NaCl}$. The first dose was given $15 \mathrm{~min}$ before the reperfusion phase (i.v), and then every two hours for one time ( $12 \mathrm{~h}$ reperfusion) or three ( $24 \mathrm{~h}$ reperfusion) times after re-flow (s.c.).

\section{Protocol 2}

First aim: to evaluate the possibility to s.c. continuously infused repertaxin by means of osmotic pumps, a phamacokinetic elaboration was done as follows.

In order to obtain a plasmatic concentration of repertaxin at the steady-state (Css) of $15 \mu \mathrm{g} / \mathrm{ml}$, the rate of infusion $\left(R_{0}\right)$ was calculated. Since repertaxin s.c. bioavailability is almost complete, $R_{0}$ was calculated according to the following formula:

$\mathrm{R}_{0}=$ Css x Kel x V (26).

The apparent volume of distribution $(\mathrm{V})$ and the elimination rate constant (Kel) of repertaxin were obtained by previous pharmacokinetic studies.

$$
\mathrm{R}_{0}=15 \times 1.82 \times 283=7726 \mu \mathrm{g} / \mathrm{h} / \mathrm{kg} \sim 8 \mathrm{mg} / \mathrm{h} / \mathrm{kg}
$$

The pump rate was $10 \mu 1 / \mathrm{h}$, to obtain $8 \mathrm{mg} / \mathrm{h} / \mathrm{kg}$ as $\mathrm{R}_{0}$ (corresponding to $2 \mathrm{mg} / \mathrm{h} / \mathrm{rat}$ ) the pumps were filled with repertaxin $200 \mathrm{mg} / \mathrm{ml}$. Pumps were implanted at the reperfusion time. In order to consider the time of pump activation and to immediately reach plasmatic Css, rats were also treated with a single i.v. injection of repertaxin $15 \mathrm{~min}$ before reperfusion. Repertaxin i.v. dose was identified by preliminary experiments and established at $15 \mathrm{mg} / \mathrm{kg}$.

Blood samples were collected at the following times: $2,4,8$ and 24 h after i.v. injection.

Second aim: to evaluate the efficacy of repertaxin administered by continuous infusion, rats were s.c. infused by means of the osmotic pumps implantation starting from the time of reperfusion with three different doses of the compound, as follows.

Group 1: i.v. dose: $4.5 \mathrm{mg} / \mathrm{kg} . \mathrm{R}_{0}: 2.4 \mathrm{mg} / \mathrm{h} / \mathrm{kg}$.

Group 2: i.v. dose: $2.5 \mathrm{mg} / \mathrm{kg}$. $\mathrm{R}_{0}: 1.2 \mathrm{mg} / \mathrm{h} / \mathrm{kg}$. 
Group 3: i.v. dose: $0.4 \mathrm{mg} / \mathrm{kg}$. $\mathrm{R}_{0}: 0.2 \mathrm{mg} / \mathrm{h} / \mathrm{kg}$.

Repertaxin i.v. dose was administered $15 \mathrm{~min}$ before reperfusion. In the vehicle group, animals were treated with $0.9 \%$ sterile $\mathrm{NaCl}$ solution (i.v. injection + pump infusion).

\section{Morphological studies}

Fragments from the reperfused left lateral lobe were placed overnight in $4 \%$ formaldehyde, $50 \mathrm{mM}$ phosphate buffer solution, $\mathrm{pH}$ 7.4. Paraffin wax sections of $5 \mu \mathrm{m}$ were stained with Harris hematoxylin and eosin. Hepatocellular morphologic criteria, i.e. nuclear changes consisting in pycnosis, karyorrhexis, or karyolysis; cytoplasmic blanching; extreme vacuolization and loss of distinct cell borders, were used to determine necrosis. PMN leukocytes were identified on $5 \mu \mathrm{m}$ paraffin sections by means of the naphthol AS-D chloroacetate technique for esterase, described elsewhere (27). Red stained PMN were counted in 20 non-consecutive, randomly chosen $x$ 400 histological fields. Results were expressed as number of PMN per histological power field (hpf).

\section{Measurement of MPO activity}

Total hepatic MPO activity was assayed by measuring the hydrogen peroxide-dependent oxidation of $O$ dianisidine described elsewhere (15). Pellets from snapfrozen samples homogenized in $20 \mathrm{mM}$ potassium phosphate buffer, pH 7.4, were re-suspended in $50 \mathrm{mM}$ potassium phosphate buffer, $\mathrm{pH} 6.0$, containing $0.5 \%$ hexadecyltrimethyl-ammonium bromide. The suspension was frozen and thawed once, sonicated, incubated at $60^{\circ} \mathrm{C}$ for $2 \mathrm{~h}$, and then centrifuged again. MPO activity was measured by mixing the supernatant with $0.05 \mathrm{M}$ potassium phosphate buffer, $\mathrm{pH} 6.0$, containing 0.167 $\mathrm{mg} / \mathrm{ml}$ o-dianisidine and $0.24 \mathrm{mM} \mathrm{H}_{2} \mathrm{O}_{2}$ (final concentration). Changes in absorbance at $460 \mathrm{~nm}$ were monitored for $2 \mathrm{~min}$ at $37^{\circ} \mathrm{C}$. One unit of MPO activity was defined as the amount of enzyme reducing 1 İmol of hydrogen peroxide/minute. The results are expressed as units of MPO/g wet tissue.

\section{ELISA assay for CINC-1/CXCLI}

Tissue and plasma levels of CXCL1 were measured by an enzyme-linked immunosorbent assay using the Rat CXCL1 Immunoassay kit (Immuno-Biological Laboratories, Gunma, Japan). Analysis was performed spectrophotometrically. Tissue levels of CXCL1 production was measured in liver homogenates. Liver tissue was homogenized in 20 volumes of homogenization buffer $(w / v)$ (25 mM Tris-HCl, $2 \mathrm{mM} \mathrm{MgCl} 2,50 \mathrm{mM}$ $\mathrm{KCl}, 10 \mathrm{mM}$ EDTA, $2 \mathrm{mM}$ phenylmethylsulfonyl fluoride, $0.1 \mathrm{mg} / \mathrm{ml}$ soybean trypsin inhibitor, $1.0 \mathrm{mg} / \mathrm{ml}$ bovine serum albumin, $0.02 \%$ sodium azide, and $10 \mu \mathrm{l} / \mathrm{ml}$ protease inhibitor cocktail $[1 \mathrm{mg} / \mathrm{ml}$ leupeptin, $1 \mathrm{mg} / \mathrm{ml}$ aprotinin, and $1 \mathrm{mg} / \mathrm{ml}$ pepstatin]). The homogenates were centrifuged at $13,000 \mathrm{~g}$ for $20 \mathrm{~min}$. Supernatants were removed, centrifuged again to obtain clear lysates and analysis of samples of plasma and clear lysates was performed spectrophotometrically. Results are expressed in $\mathrm{ng}$ (tissue)-pg (plasma)/ml.

\section{Biochemical assessment of liver cytolysis}

The plasma activity of alanine aminotransferase (ALT) was evaluated using a commercial kit from Sigma Chemical Co. (St. Louis MO). Results are expressed in $\mathrm{U} / 1$.

\section{Statistical Analysis}

Values are expressed as means \pm S.E.M or S.D. Oneway analysis of variance and Tukey-Kramer test adjustment for multiple comparisons were used, unless otherwise stated, the alternative being an unpaired Student's $t$ test. $p$ values $\leq 0.05$ were considered statistically significant. The correlation between number of PMN and levels of ALT was tested by the nonparametric (Spearman) correlation coefficient.

\section{RESULTS}

Efficacy of repertaxin repeated administrations in preventing hepatic reperfusion injury

We first evaluated the efficacy of repeated administrations of repertaxin in preventing tissue damage in post-ischemic rat liver $24 \mathrm{~h}$ after reperfusion. To this end, we initially evaluated the pharmacokinetic profile of repertaxin in rats exposed to liver ischemia/reperfusion injury at a dose of the compound $(15 \mathrm{mg} / \mathrm{kg})$ and with a schedule of treatment (i.v. $15 \mathrm{~min}$ before reperfusion and s.c. $2 \mathrm{~h}$ after reperfusion) previously reported to protect against hepatocellular necrosis $12 \mathrm{~h}$ after reperfusion (23). As shown in Fig. 1, repertaxin plasmatic concentration peaked at $2 \mathrm{~h}$ after reperfusion (34 $\mu \mathrm{g} / \mathrm{ml}$ ) and was deteclable up to $8 \mathrm{~h}$ after reperfusion $(30 \mathrm{ng} / \mathrm{ml})$. These data are in agreement with the pharmacokinetic profile of repertaxin determined in normal rats (half-life almost $35 \mathrm{~min}$; data not shown), suggesting that additive administrations were necessary to evaluate its efficacy at a longer time (24h) after reperfusion.

Next, we evaluated the efficacy of repertaxin in preventing PMN infiltration and tissue damage in the 
post-ischemic hepatic lobes $12 \mathrm{~h}$ and $24 \mathrm{~h}$ after re-flow onset. PMN infiltration was quantified through a histochemical method, which allows to identify and count red-stained leukocytes, and by evaluating MPO activity in liver extracts. Liver specimens from rats treated with vehicle alone undergoing $60 \mathrm{~min}$ of ischemia followed by $12 \mathrm{~h}$ and $24 \mathrm{~h}$ of reperfusion had a significantly increased of PMN content (Fig. 2 A) and MPO activity (Fig. 2 B) versus sham-operated animals. As shown in Figure $2 \mathrm{C}$, the degree of hepatocellular necrosis, in terms of activity of ALT in plasma, indicated substantial liver damage. As expected, rats treated with two repeated administrations of repertaxin $(15 \mathrm{mg} / \mathrm{kg}$; i.v. $15 \mathrm{~min}$ before reperfusion and s.c. $2 \mathrm{~h}$ after reperfusion) were protected against $\mathrm{PMN}$ infiltration and hepatocellular damage at $12 \mathrm{~h}$ after reperfusion (Fig. $2 \mathrm{~A}-\mathrm{C} ; 23$ ).

On the contrary, repertaxin administration with the same schedule of treatment was observed to be efficacious at $12 \mathrm{~h}$ after reperfusion $(15 \mathrm{mg} / \mathrm{kg}$; i.v. 15 $\min$ before reperfusion and s.c. $2 \mathrm{~h}$ after reperfusion) did not reduced PMN infiltration and hepatocellular damage at $24 \mathrm{~h}$ after reperfusion (data not shown).

According to the pharmacokinetic profile of repertaxin (see Fig. 1), rats exposed to $24 \mathrm{~h}$ of reperfusion were treated with the compound (15 $\mathrm{mg} / \mathrm{kg}$ ) $15 \mathrm{~min}$ before reperfusion and every two hours after reperfusion for an additional three times. With this schedule of treatment rat livers were efficiently protected against PMN infiltration and the deleterious consequence of the post-ischemic inflammatory reaction, as the degree of hepatocellular necrosis was attenuated by $86 \%$ (Fig. 2 A-C). Direct positive correlations were found among the number of red-stained leukocytes and the degree of necrosis, stressing the concept that the extension of hepatocellular damage and death found $24 \mathrm{~h}$ after reperfusion depends on the degree of PMN infiltration (Table I).

Since CXCL1 plays a central role in recruitment of PMN in the liver and in their transmigration from the vascular space to the close proximity of the

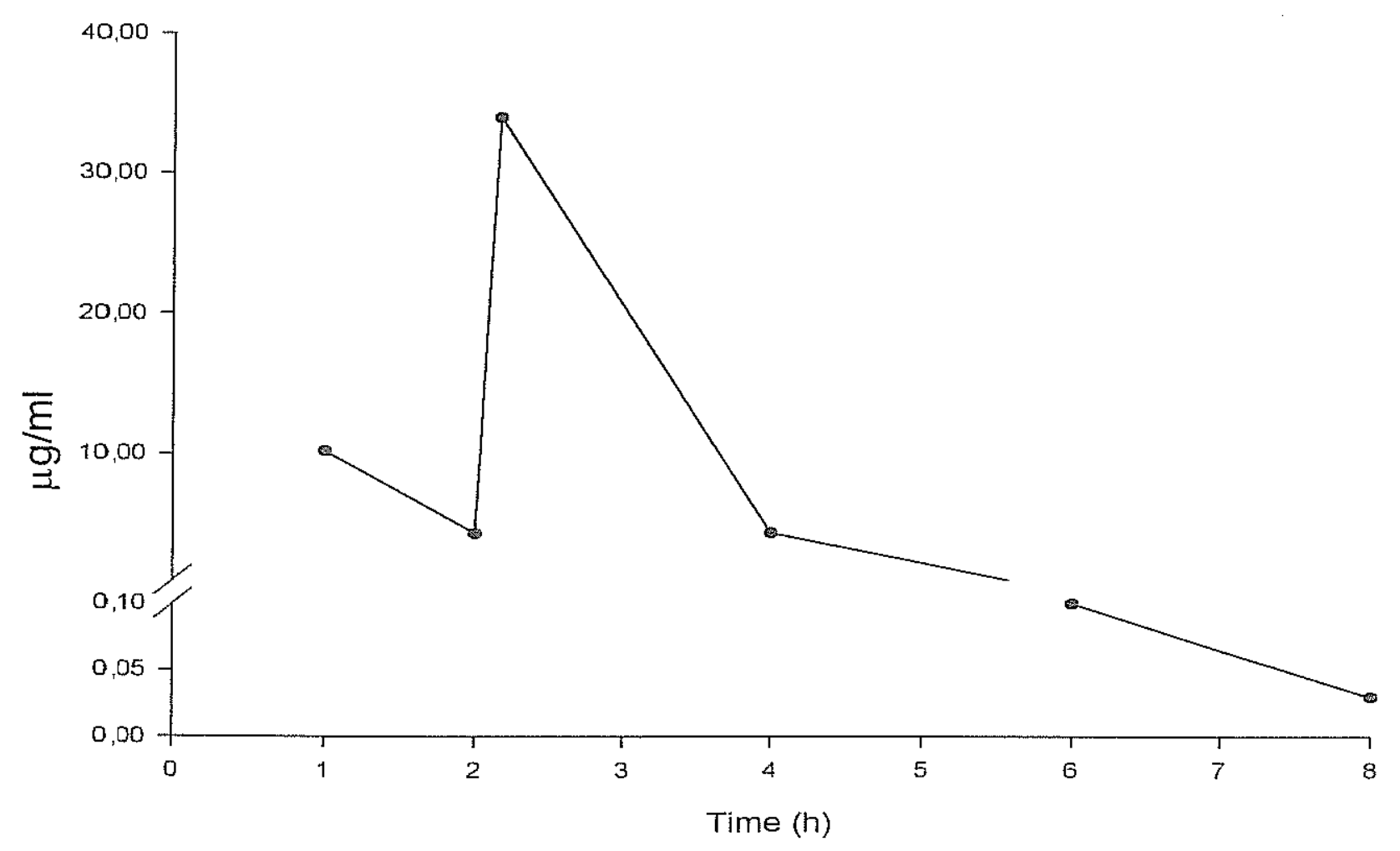

Fig. 1. Plasmatic concentrations of repertaxin after repeated administrations. Animals exposed to liver ischemia/reperfusion were treated with repertaxin $(15 \mathrm{mg} / \mathrm{kg}) 15 \mathrm{~min}$ before reperfusion (i.v.) and $2 \mathrm{~h}$ (s.c.) after reperfus ion. Plasmatic levels of the compound were determined at different times after i.v. injection, as described in Materiazs and Methods section. Each experimental determination is the mean of three animals. 

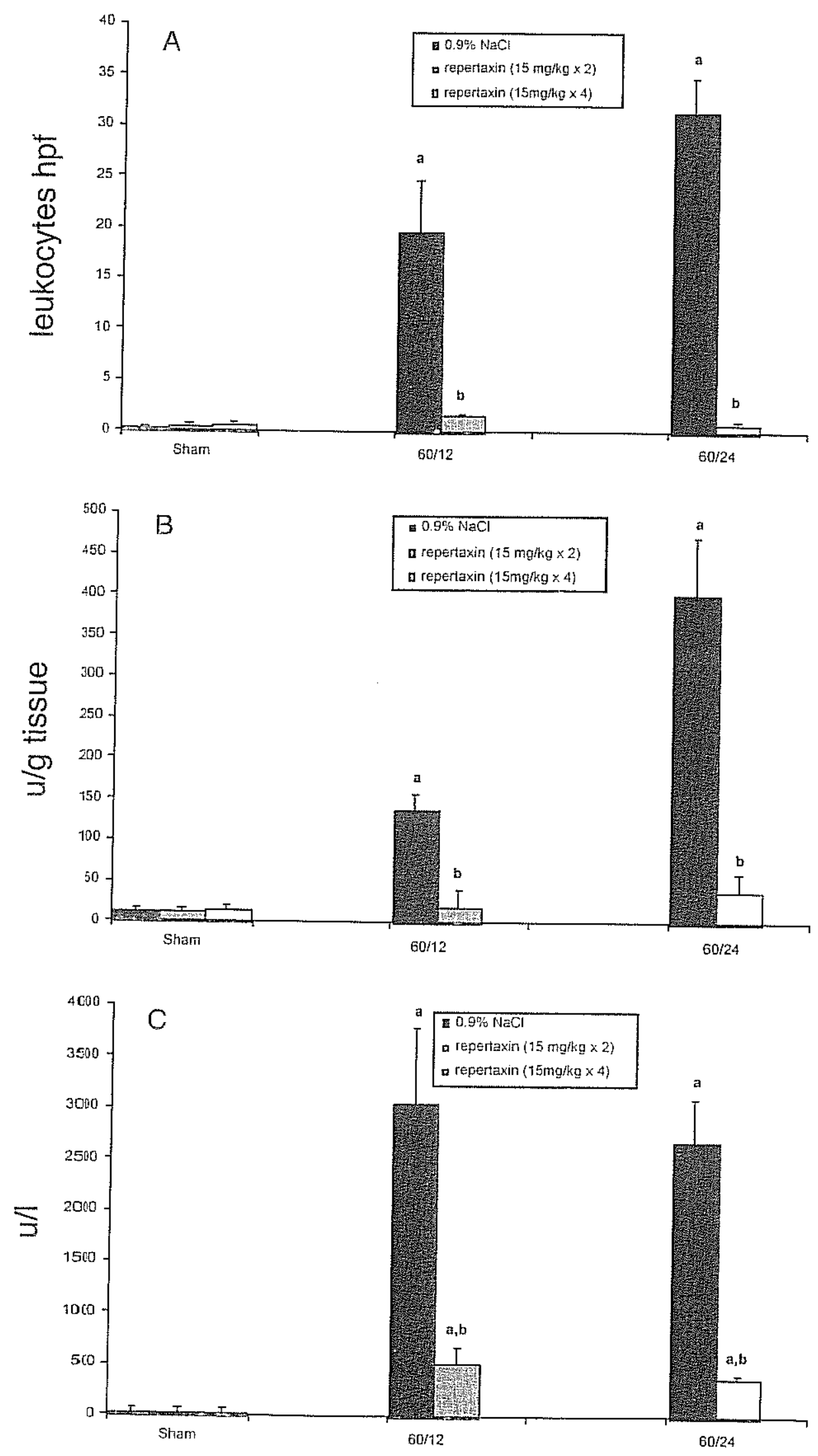

Fig. 2. Efficacy of repeated administrations of repertaxin in attenuating PMN infiltration and hepatocellular necrosis in post-ischemic rat livers. PMN recruitment in the post-ischenic liver was assessed by letkocyte counts (A) and by MPO activity (B). Hepatic irreversible damage was evaluated by means of plasma ALT levels (C). 60/12-24: rats submitted to 60 min of ischemia and 12 or $24 \mathrm{~h}$ of reperfision. Rats were treated with vehicle or repertaxin (15 $\mathrm{mg} / \mathrm{kg})$ as described in Materials and Methods section. Data are expressed as mean \pm S.E.M. $(n=5)$.

a: rats submitted to ischemia/reperfision injury vs sham. b: repertaxin treated rats us vehicle treated rats.

A: vehicle and repertaxin treated us sham, $p<0.01$; velicle is repertaxin treated, $p<0.01$.

$B$ : velicle and repertaxin treated is sham, $p<0.05$; velicle us repertaxin treated, $p<0.01$.

$C:$ vehicle and repertaxin treated us sham, $p<0.01$; vehicle is repertaxin treated, $p<0.01$. 

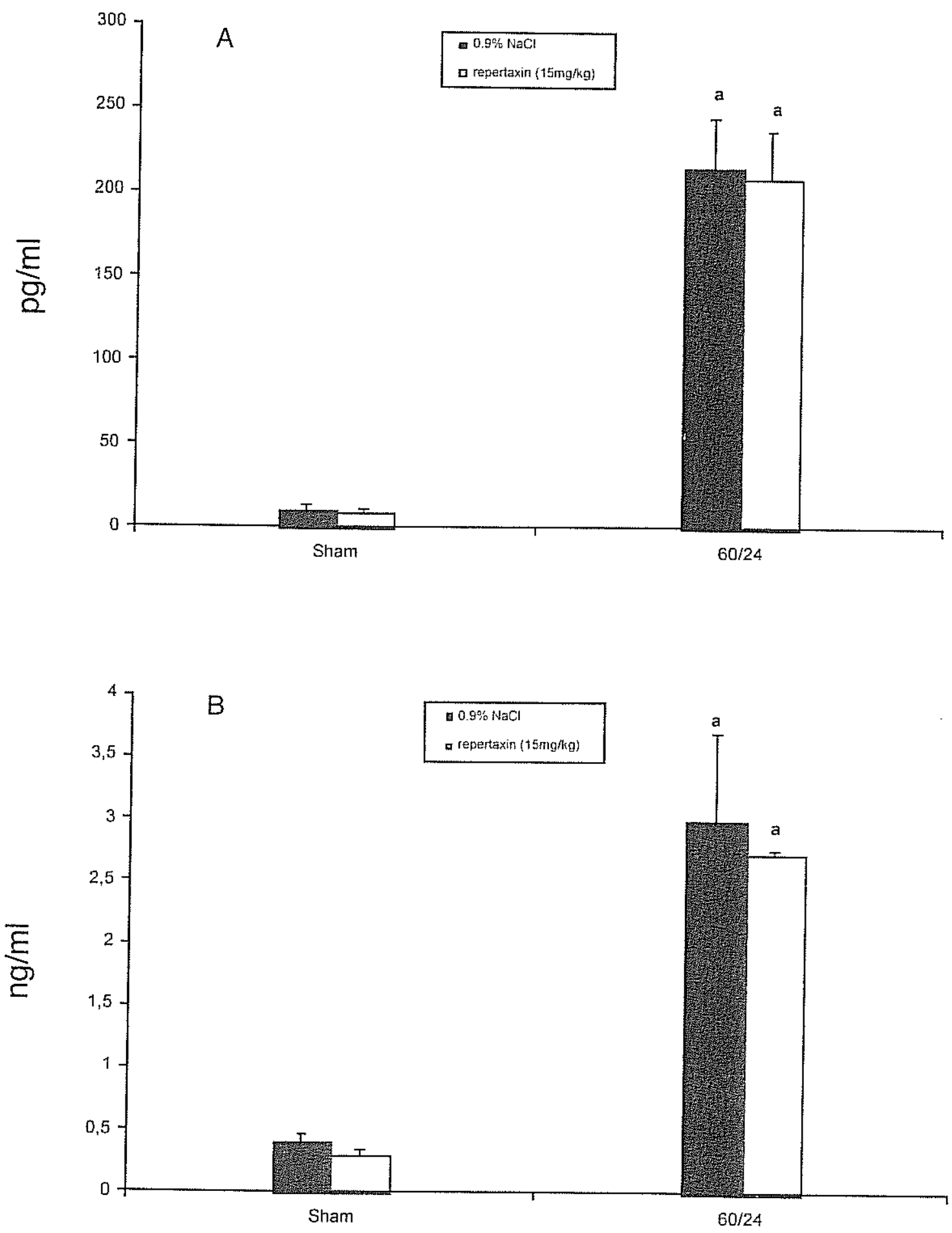

Fig. 3. Repertaxin does not affect CINC-I/CXCL1 production. 60/24: rats were submitted to 60 min of ischemia followed by 24 h of reperfision. Animals were treated with vehicle or repertaxin $(15 \mathrm{mg} / \mathrm{kg}$; four repeated administrations, see Materials and Methods section). Data are expressed as mean $\pm S . E . M$. (n=5). Plasma (A) and hepatic (B) levels of CINC-1/CXCL1. a: rats submitted to ischemia/reperfision injury vs sham, $p<0.01$. 


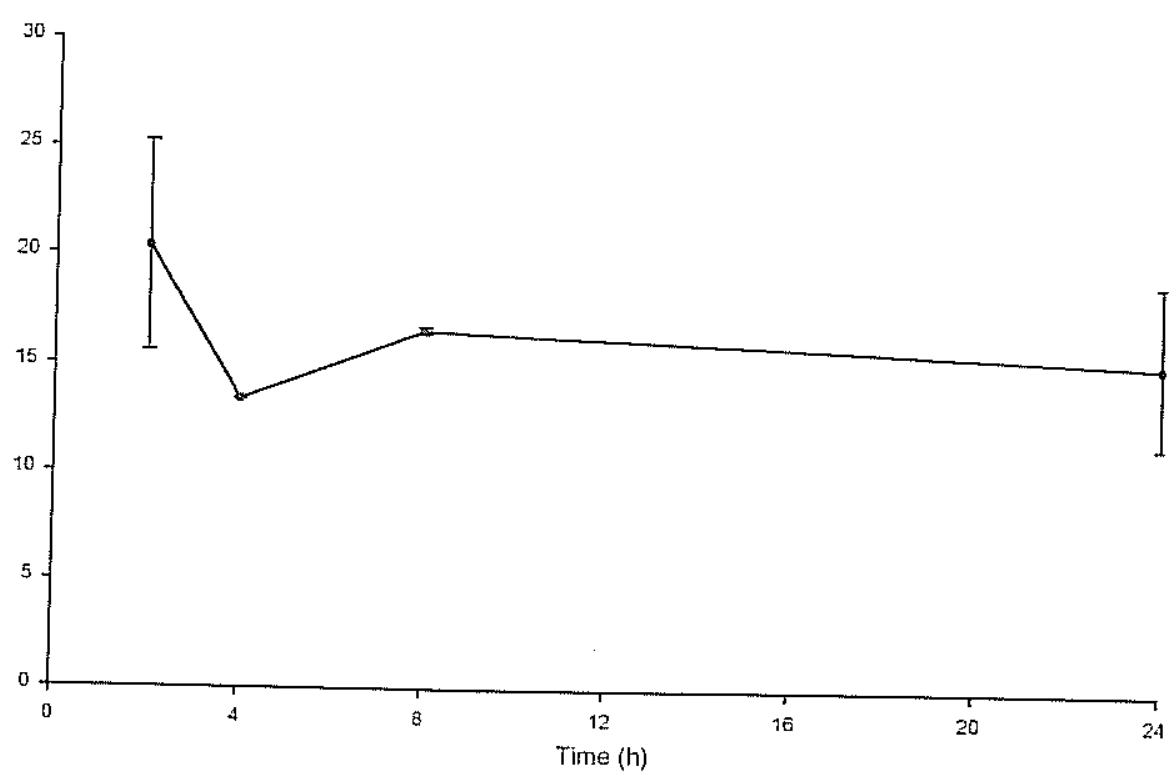

Fig. 4. Plasmatic concentrations of repertaxin after continuous infusion administration. Rats exposed to liver ischemial reperfusion were treated with repertaxin $15 \mathrm{mg} / \mathrm{kg}$ i.v. $15 \mathrm{~min}$ before reperfusion and $8 \mathrm{mg} / \mathrm{h} / \mathrm{kg}$ by s.c. continuous infusion starting from the time of reperfusion. Plasmatic levels of the compound were determined at different times after reperfusion, as described in Materials and Methods section. Each experimental determination is mean \pm S.D. of three animals. hepatic parenchymal cells (21), levels of this CXCchemokine were evaluated in plasma and tissue samples. Reperfusion of ischemic liver significantly induced CXCL1 production both in plasma and in tissue (Fig. 3 A-B). In keeping with its molecular mechanism of action (23), repertaxin did not affect CXCL1 production (Fig. $3 \mathrm{~A}-\mathrm{B}$ ).

\section{Repertaxin hepatocellular protection after continuous infision treatment}

The requirement of multiple doses of repertaxin treatment to prevent reperfusion injury suggests that administration by continuous infusion of the compound could be the optimal schedule of treatment to be used, mainly in view of a potential clinical therapeutical use of the compound. To assess the efficacy of repertaxin by continuous infusion in preventing hepatic reperfusion injury, we first evaluated the possibility to continuously infuse repertaxin by s.c. rat implantation of osmotic pumps. Since repertaxin s.c. bioavailability is almost complete (data not shown), rats were treated with repertaxin at a $R_{0}$ of $8 \mathrm{mg} / \mathrm{h} / \mathrm{kg}$ supposed to reach a plasmatic Css of about $15 \mu \mathrm{g} / \mathrm{ml}$ (see Material and Methods section, Protocol 2). As shown in Fig. 4, comparable plasmatic levels of repertaxin was observed during the time course of the infusion period. Plasmatic levels of repertaxin were in the range of predicted Css. Then, we evaluated the efficacy of repertaxin in preventing hepatic reperfusion injury at three different $R_{v}(2.4 \mathrm{mg} / \mathrm{h} / \mathrm{kg}$, $1.2 \mathrm{mg} / \mathrm{h} / \mathrm{kg}$ and $0.2 \mathrm{mg} / \mathrm{h} / \mathrm{kg}$ ) of the compound. Repertaxin treatment at $R_{0}$ of $2.4 \mathrm{mg} / \mathrm{h} / \mathrm{kg}$ and 1.2 $\mathrm{mg} / \mathrm{h} / \mathrm{kg}$ practically blocked post-ischemic PMN recruitment ( $96 \%$ of inhibition) at $24 \mathrm{~h}$ after re-flow (Fig. $5 \mathrm{~A}$ ). In correspondence, animals also showed a substantial degree of hepatocellular protection, as indicated by the $80 \%$ decrease in the extent of necrosis (Fig. $5 \mathrm{~B}$ ). On the contrary, repertaxin treatment with a $R_{\mathrm{o}}$ of $0.2 \mathrm{mg} / \mathrm{h} / \mathrm{kg}$ was less effective (33\% and $50 \%$ of inhibition of PMN infiltration and ALT plasmatic levels, respectively; Fig. 5 A-B).

The histopathological study of the hepatic lobes after ischemia/reperfusion was evaluated based on PMN infiltration and hepatocellular necrosis. In vehicle treated rats, reperfusion of the ischemic lobes induced multifocal and confluent areas of coagulative necrosis deeply delimited and infiltrated by PMN (Fig. 6A-B). On the other hand, repertaxin treatment conferred protection against hepatic reperfusion injury, as only scattered foci of hepatocyte necrosis were observed (Fig. 6 C-D). The dramatic reduction observed by repertaxin treatment in the degree of PMN infiltration (Fig. 6 C-D) further stressed the idea of a central role playing by the post-ischemic inflammatory reaction to the extent of irreversible injury to the liver. Plasmatic levels of repertaxin were also determined at the end of the infusion period. As shown in Table II, plasmatic concentration of repertaxin obtained by infusion treatments was in the 

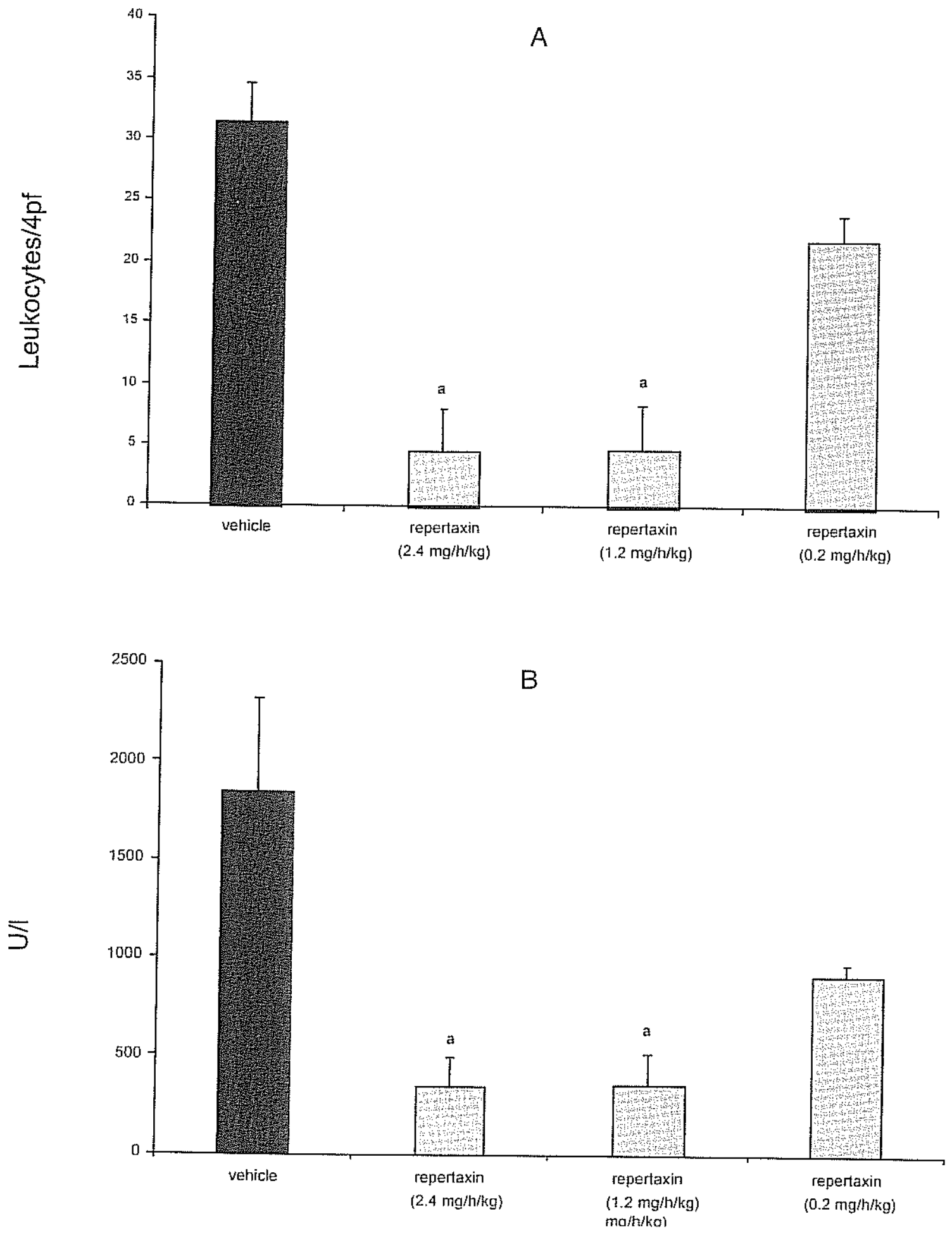

Fig. 5. Repertaxin hepatocellular protection after continuous infusion treatment. The efficacy of repertaxin by s.c. continuous infusion was evaluated at three different Ro treatments, as described in Materials and Methods section. (A) $P M N$ rechitment and $(B)$ ALT levels. Data are expressed as mean \pm S.E.M. $(n=5)$. a: repertaxin treated rats vs vehicle treated rats, $p:<0.01$. 

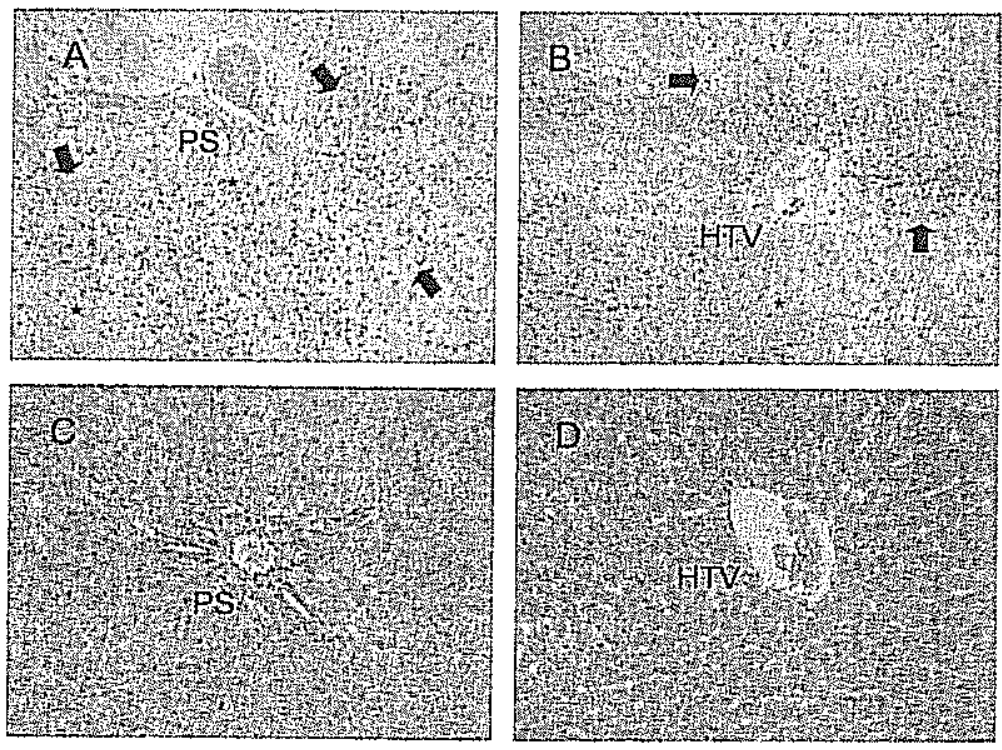

Fig. 6. Histopathology of hepatic lobes after ischemia/reperfusion damage. Efficacy of repertaxin treatment.

$A$-C: periportal areas; $B-D$ : perivenular areas. Hepatic lobes were submitted to $60 \mathrm{~min}$ of ischemia followed by $24 h$ of reperfusion. Hepatocellular necrosis, sinusoidal dilatation and leukacyte infiltration were evaluated in the liver from vehicle ( $A$ and $B$ ) or repertaxin ( $C$ and $D$ ) treated animals. Arrows point PMN infiltration and asterisks indicate necrotic hepatocytes. (Naphtol AS-D chloroacetate technique counterstained with hematoxylin, $x_{2} 00$ ). range of $0.3-7.2 \mu \mathrm{g} / \mathrm{ml}$. Repertaxin treatment did not affect blood leukocyte levels in all the ranges of $R_{0}$ tested (data not shown). No inflammatory reaction was observed around the implanted pumps at the end of the infusion period (data not shown).

\section{DISCUSSION}

Liver transplantation has become an accepted therapy for end-stage liver diseases, but graft injury after reperfusion has been one of the critical problems to overcome because of poor immediate graft function, a risk that notably increases when marginal donor liver are used (prolonged cold ischemia storage, severe fatty change), represents a persistent problem and contributes to mortality rates (28-30). During the last years it has become increasingly evident that, at the base of the early graft injury and poor function, the organization of a post-ischemic inflammatory reaction plays a pivotal role $(9,31-32)$.

Consistent with the physiopathological roles played in reperfusion injury by the hepatic gradient of CXC clemokines and related PMN infiltration, antichemoline strategies have proven to be successful (21-22). Repertaxin is the first low molecular weight inhibiter of CXCL8 in clinical development. This molecule is a potent and specific inhibitor of CXCL8mediated chemotaxis that binds to CXCR $1 / 2$ inducing a conformational constrain in the transmembrane region of the receptor, thus preventing receptor- induced signal transduction (23). Repertaxin exploits a new concept in the pharmacological inhibition of GPCRs, namely the non-competitive allosteric blocking of receptor activation.

In this paper we have initially characterized repertaxin in terms of its pharamacokinetic profile in an experimental model of liver ischemia/reperfusion injury. Furthermore, we have demonstrated repertaxin efficacy in preventing post-ischemic injury 24 hours after reperfusion, a crucial experimental and clinical end point of reperfusion (24). Finally, we have identified the optimal schedule of treatment of repertaxin in the same experimental conditions.

Our results demonstrate that repeated administrations of the compound are necessary to maintain its therapeutic effect. Moreover, in keeping with its chemical reactivity (23), sustained plasmatic levels of repertaxin are necessary to exert its protective action. Since the requirement of multiple doses of repertaxin could be technically inappropriate in view of a therapeutic use of the compound, the finding that treatment by continuous infusion was efficacious in preventing reperfusion injury strongly indicates that repertaxin is in fact a candidate novel therapeutic agent for the prevention and treatment of post-ischemic injury.

Our data prove that treatment with repertaxin by continuous infusion blocked the evolving late phase of reperfusion injury by inhibiting PMN recruitment in the post-ischemic liver (up to $96 \%$ of inhibition). 
In addition, reperfused livers from rats treated with continuous infusion of repertaxin also had an almost well preserved structure and only scattered foci of hepatocellular necrosis were seen, but no PMN were identified inside or around them. Along the same line, repertaxin administration by continuous infusion has proven safe and well tolerated in different animal studies and in phase I studies in human volunteers (data not shown). Finally, repertaxin experimental efficacy was obtained in a range of plasmatic Css superimposable to Css observed in phase I volunteers, showing the possibility to evaluate repertaxin clinical efficacy in the same range of plasmatic Css proved to be efficacious in preventing experimental reperfusion injury.

The almost complete protection afforded by repertaxin treatment in this experimental rat model of reperfusion liver damage is a main goal, but also stresses, once more, the concept that post-ischemic injury is the consequence of the organization of an acute inflammatory response. Therefore, strategies aimed to block the activation of receptors for chemoattractant receptors, as repertaxin does, appear as new therapeutic approaches in the attempt to control inflammation evoked by ischemia/reperfusion insults.

In summary, we found that repertaxin, a new small-molecule inhibitor of CXCL8 receptor activation, is effective in preventing rat hepatocellular necrosis induced by a clinical-relevant time of reperfusion. According to the pharmacokinetic profile of repertaxin and its chemical-physical properties, treatment by continuous infusion was demonstrated to be the optimal route of administration of the compound. Because repertaxin has been proven safe and well tolerated in different animal studies and in phase 1 studies in human volunteers, it is in fact a candidate novel therapeutic agent for the prevention and treatment of post-ischemic injury. The protection afforded by repertaxin points to the relevance of CXCL\& as a pharmacological target to prevent lethal reperfusion injury due to PMN infiltration.

\section{REFERENCES}

1. Fan C., R.M. Zwacka and J.F. Engelhardi. 1999. Therapeutic approaches for ischemia-reperfusion Injury in the liver. J. Mol. Med. 77:577.
2. Jaeschke H. 1998. Mechanisms of reperfusion injury after warm ischemia of the liver. $J$. Hepatobiliary Pancreat. Surg. 5:402.

3. Henderson J.M. 1999. Liver transplantation and rejection: an overview. Hepatogastroenterology $46(S): 1482$.

4. Jaeschke H. 1996. Preservation injury: mechanisms, prevention and consequences. J. Hepatol. 25:774.

5. Strasberg S.M., T.K. Howard, E.P. Molmenti and M. Hertl. 1994. Selecting the donor liver: risk factors for poor function after orthotopic liver transplantation. Hepatology 20:829.

6. Furukawa H., S. Todo, O. Inventarza, et al. 1991. Effect of cold ischemia time of early outcome of human hepatic allografts preserved with UW solution. Transplantation 51:1000.

7. Clavien P.A., P.R. Harvey and S.M. Strasberg. 1992. Preservation and reperfusion injury in liver allografts. Another view and synthesis of current studies. Transplantation 53:957.

8. D'Alessandro A.M., M. Kalayoglu, H.W. Sollinger, et al. 1991. The predictive value of donor liver biopsies for the development of primary nonfunction after orthotopic liver transplantation. Transplant. Proc. 23:1536.

9. Gu X.P., Y. Jiang, F.T. Xu, Y.D. Qiu and Y.T. Ding. 2004. Effect of cold ischemia time on nuclear factor- $\mathrm{kB}$ activation and inflammatory response in graft after orthotopic liver transplantation in rats. World J. Gastroenterol. 10:1000.

10. Okaya T. and A.B. Lentsch. 2003. Cytokine cascade and hepatic inflammatory response to ischemia and reperfusion. J. Invest. Surg. 16:141.

11. Lentsch A.B., H. Yoshidone, W.G. Cheadle, F.N. Miller and M.J. Edwards. 1998. Chemokine involvement in hepatic ischemia/reperfusion injury in mice: roles for macrophage inflammatory protein-2 and KC. Hepatology 27:507.

12. Colletti L.M., S.L. Kunkel, A. Walz, M.D. Burdick, R.G. Kunkel, C.A. Wilke and R.M. Strieter. 1996. The role of cytokine networks in the local liver injury following hepatic ischemia/reperfusion in the rat. Hepatology 23:506.

13. Hisama N., Y. Yamaguchi, T. Ishiko, et al. 1996. Kupffer cell production of cytokine-induced neutrophil 
chemoattractant following ischemia/reperfusion injury in rats. Hepatology 24:1193.

14. Mawet E., Y. Shiratori, Y. Hikiba, et al. 1996. Cytokine-induced neutrophil chemoattractant release from hepatocytes is modulated by Kupffer cells. Hepatology 23:353.

15. Cutrìn J.C., A. Boveris, B. Zingaro, G. Corvetti and G. Poli. 2000. In situ determination by surface chemiluminescence of temporal relationships between evolving warm ischemia-reperfusion injury in rat liver phagocyte activation and recruitment. Hepatology 31:622.

16. Lentsch A.B., A. Kato, H. Yoshidome, K.M. McMasters and M.J. Edwards. 2000. Inflammatory mechanisms and therapeutic strategies for warm hepatic ischemia/reperfusion injury. Hepatology 32:169.

17. Kushimoto S., K. Okajima, M. Uchiba, K. Murakami, N. Harada, $H$. Okabe and $K$. Takatsuki. 1996. Role of granulocyte elastase in ischemia/reperfusion injury of rat liver. Crit. Care Med. 24:1908.

18. Jaeschke H. and A. Farhood. 1991. Neutrophil and Kupffer cell induced oxidant stress and ischemiareperfusion injury in rat liver. Am. J. Physiol. 260:G335.

19. Jaeschke H. and A. Farhood. 1990. Neutrophils contribute to ischemia/reperfusion injury in rat liver. FASEB J. 4:3355.

20. VolImar B., J. Glasz, S. Post and M.D. Menger. 1994. Hepatic microcirculatory perfusion failure is a determinant for liver dysfunction in warm ischemia reperfusion. An. J. Pathol. 145:1421.

21. Proudfoot A.E. 2002. Chemokine receptors: multifaceted therapeutic targets. Nature Rev. Immunol. 2:106.

22. Howard O.M., J.J. Oppenheim and J.M. Wang. 1999. Chemokines as molecular targets for therapeutic intervention. J. Clin. Immtnol. 19:280.

23. Bertini R., M. Allegretti, C. Bizzarri, et al. 2004. Noncompetitive allosteric inhibitors of the inflammatory chemokine receptors CXCR1 and CXCR2: prevention of reperfusion injury. PNAS 101:11791.

24. Gujral J.S., T.J. Bucci, A. Farhood and $H$. Jaeschke. 2001. Mechanism of cell death during warm hepatic ischemia-reperfusion in rats: apoptosis or necrosis? Hepatology 33:397.

25. Cavalieri B., M.G. Perrelli, M. Aragno, R. Mastrocola, G. Corvetti, M. Durazzo, G. Poli and J.C. Cutrìn. 2002. Ischemic preconditioning attenuates the oxidant-dependent mechanisms of reperfusion cell damage and death in rat liver. Liver Transpl. 8:990.

26. Rowland M. and T.N. Tozer. 1995. Clinical Pharmacokinetics. In Concepts and Applications. Third ed. Lippincott Williams and Wilkins. Philadelphia, p.1

27 Schleyer H.J., H. Laaff, T. Peters, M. WoortMenker, H.C. Estler, U. Karck, H.E. Schaefer and K. Decker. 1988. Involvement of tumor necrosis factor in endotoxin-triggered neutrophil adherence to sinusoidal endothelial cells of mouse liver and its modulation in acute phase. J. Hepatol. 7:239.

28. Selzner M. and P.A. Clavien. 2001. Fatty liver in liver transplantation and surgery. Semin. Liver Dis. 21:105.

29. Trevisani F., A. Colantoni, P. Caraceni and D.H. Van Thiel. 1996. The use of donor fatty liver for liver transplantation: challenge or a quagnire? J. Hepatol. 22:114.

30. Todo S., A.J. Demetris, I. Makowaka, I. Teperman, L. Podesta, T. Shaver, A. Tzakis and T.E. Starlz. 1989. Primary nonfunction of hepatic allografts with preexisting fatty infiltration. Transplantation 47:903.

31. Kataoka M., H. Shimizu, N. Mitsuhashi, et al. 2002. Effect of cold-ischemia time on CXC chemokine expression and neutrophil accumulation in the graft liver after orthotopic liver transplantation in rats. Transplantation 73:1730.

32. Martinez-Mier G., L.H. Toledo-Pereyra, J.E. McDuffie, R.L. Warner and P.A. Ward. 2001. Neutrophil depletion and chemokine response after liver ischemia and reperfusion. J. Invest. Surg. 14:99. 